\title{
Longitudinal (UT) effect in the onset of auroral disturbances over two solar cycles as deduced from the AE-index
}

\author{
L. A. Hajkowicz \\ Department of Physics, University of Queensland, Qld. 4072, Australia
}

Received: 6 October 1997 / Revised: 4 May 1998 / Accepted: 15 May 1998

\begin{abstract}
Statistical study on the universal time variations in the mean hourly auroral electrojet index (AEindex) has been undertaken for a $21 \mathrm{y}$ period over two solar cycles (1957-1968 and 1978-1986). The analysis, applied to isolated auroral substorm onsets (inferred from rapid variations in the AE-index) and to the bulk of the AE data, indicates that the maximum in auroral activity is largely confined to $09-18$ UT, with a distinct minimum at 03-06 UT. The diurnal effect was clearly present throughout all seasons in the first cycle but was mainly limited to northern winter in the second cycle. Severe storms $(\mathrm{AE}>1000 \mathrm{nT})$ tended to occur between 9-18 UT irrespective of the seasons whereas all larger magnetic disturbances $(\mathrm{AE}>500 \mathrm{nT})$ tended to occur in this time interval mostly in winter. On the whole the diurnal trend was strong in winter, intermediate at equinox and weak in summer. The implication of this study is that Eastern Siberia, Japan and Australia are mostly at night, during the period of maximum auroral activity whereas Europe and Eastern America are then mostly at daytime. The minimum of auroral activity coincides with near-midnight conditions in Eastern America. It appears that the diurnal UT distribution in the AE-index reflects a diurnal change between interplanetary magnetic field orientation and the Earth's magnetic dipole inclination.
\end{abstract}

Key words. Ionosphere (auroral ionosphere), Magnetospheric physics (auroral phenomena; storms and substorms).

\section{Introduction}

There is growing evidence that the onset of auroral activity has a distinct universal time effect, i.e. it tends to occur predominantly in a certain longitudinal sector. An early study of the longitudinal dependence in auroral particle precipitation was conducted by Loughnan (1961) who suggested that there is a marked longitudinal leakage of auroral particles from the trapped-radiation regions. An experimental particle observation project from a satellite has revealed a large universal-time variation in low-energy electron fluxes (Maehlum, 1968). $\mathrm{He}$ associated these variations with the diurnal changes in the tilt of the Earth's geomagnetic axis relative to the solar wind direction. Stenbaek-Nielsen (1974) reported that there is a substantial longitudinal difference in the precipitation of electrons with energy in excess of $40 \mathrm{keV}$ over Alaska and Scandinavia. Electron flux over Alaska was 2-4 times higher than over Scandinavia supporting the riometer absorption studies by Basler (1963) and Driatskiy (1966). The latter found that auroral absorption over College, Alaska to be twice that over Scandinavia and eastern Canada. Berkey (1973) supported this finding by an additional riometer study. Allen and Kroehl (1975) investigated the auroral electrojet index (AE-index) for one year (1970) at 2.5 min intervals. They found a broad maximum in the auroral disturbance at 12-21 UT, particularly prominent in summer. Finally Basu (1975) studied the behaviour of the negative component of AE-index i.e. AL-index for 3 y (1968-1970). She found a distinct UT pattern in the occurrence of auroral disturbances, particularly during northern winter.

The longitudinal component in the auroral disturbances has been noted by Hajkowicz (1992, 1995, 1996). It became evident that onset of auroral substorms, as inferred from the hourly auroral electrojet index AE, was most frequent between 13-19 UT in the declining phase of a solar cycle (1980-1985). Over $30 \%$ of the distinct peaks (numbering 580) in the AE-index occurred in a relatively narrow region 13-16 UT (Hajkowicz, 1996). This study was linked with the occurrence of large-scale ionospheric disturbances (LSTIDs) which invariably follow the onset of auroral substorms. It became evident that the predominant onset of auroral substorms was close to the local average midnight 
(13.5 UT) at the Japanese, Eastern Siberian and Australian ionosonde chain locations, used for tracing LSTIDs. Although this universal time effect has important implications for the ionospheric disturbance generation and propagation study it also points to a more fundamental feature in the morphology of auroral substorms. Thus, the previous limited study of the AEindex variations was extended to 2 solar cycles spanning $21 \mathrm{y}$ of auroral electrojet intensity variations.

\section{Method and results}

The auroral electrojet index (AE), originally introduced by Davis and Sugiura (1966), is a measure of the global electrojet activity in the auroral zone. The index is computed from the horizontal component of geomagnetic variations observed at 10-13 observatories positioned in the northern auroral zone (see Allen and Kroehl, 1975; Mayaud, 1980, for detailed discussion of the positions of various stations). The most positive value of the component is called the AU index and the most negative the AL-index. These indices provide instantaneous measures of eastward and westward electrojet currents, such that $\mathrm{AE}=\mathrm{AU}-\mathrm{AL}$. Thus, $\mathrm{AE}$ indicates the total maximum amplitude of the twocurrent-system. In this study hourly averages of the 2.5-min values of $\mathrm{AE}$ indices were used.

The study herewith presented was based on simple statistical analysis but extended over a long period. The data was divided to seasonal and solar cycle segments to deduce the average and median trends in the auroral electrojet activity at specific time intervals. Some individual substorms onsets were also used to illustrate the strong diurnal effect in the real-time hourly values of AE-indices.

The longitudinal effect in the occurrence of isolated auroral substorm onsets, inferred from well-defined peaks in the hourly average AE-indices, can be seen from examples shown in Fig. 1. The selected peaks occurred here in periods centred at 12 UT (Fig. 1a) and 16 UT (Fig. 1b). The arrow (used on all the graphs) indicates the local average midnight (abbreviated as LM, at 13.5 UT) at the Australian-Japanese and Eastern Siberian longitudinal sector (in association with the previous study on LSTIDs, (see the Introduction), here referred to as sector 1 .

Altogether 33 isolated peaks (of the form shown in Fig. 1) were found over the period 1980-1988. Statistical analysis for all the selected events is shown in Fig. 2. The peak in the median AE value is at 12-14 UT (close to LM) showing the preferential UT component in the occurrence of isolated substorms (Fig. 2a). Figure $2 b$ shows the maximum hourly AE values found for each hour of the 33 day data (i.e. each hour in the interval 0-23 UT for each day was scanned for a single maximum value). It can be seen that the more enhanced substorms (AE > $800 \mathrm{nT}$ ) occurred at 08-16 UT.

The selective nature in the occurrence of substorms for a relatively short period (1980-1985) has been well documented (Hajkowicz 1992, 1996). Since there seems to be no evidence concerning this type of study
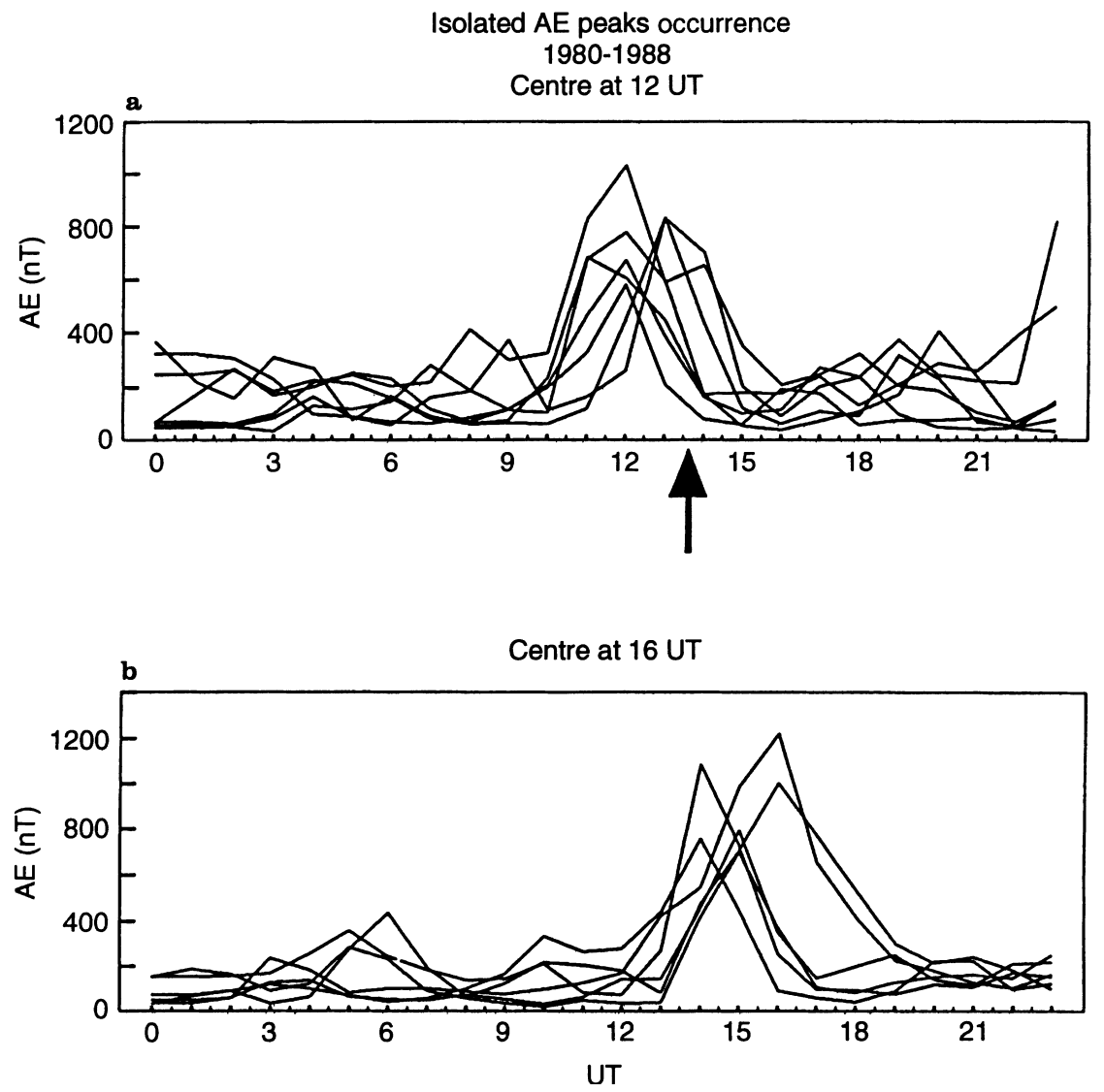

Fig. 1a,b. Examples of preferred occurrence times of some isolated substorm onsets at 19801988, as inferred from the hourly AE-indices. The mean midnight of the Eastern SiberiaJapan-Eastern Australia (sector 1) is indicated by the arrow (repeated on other graphs) 

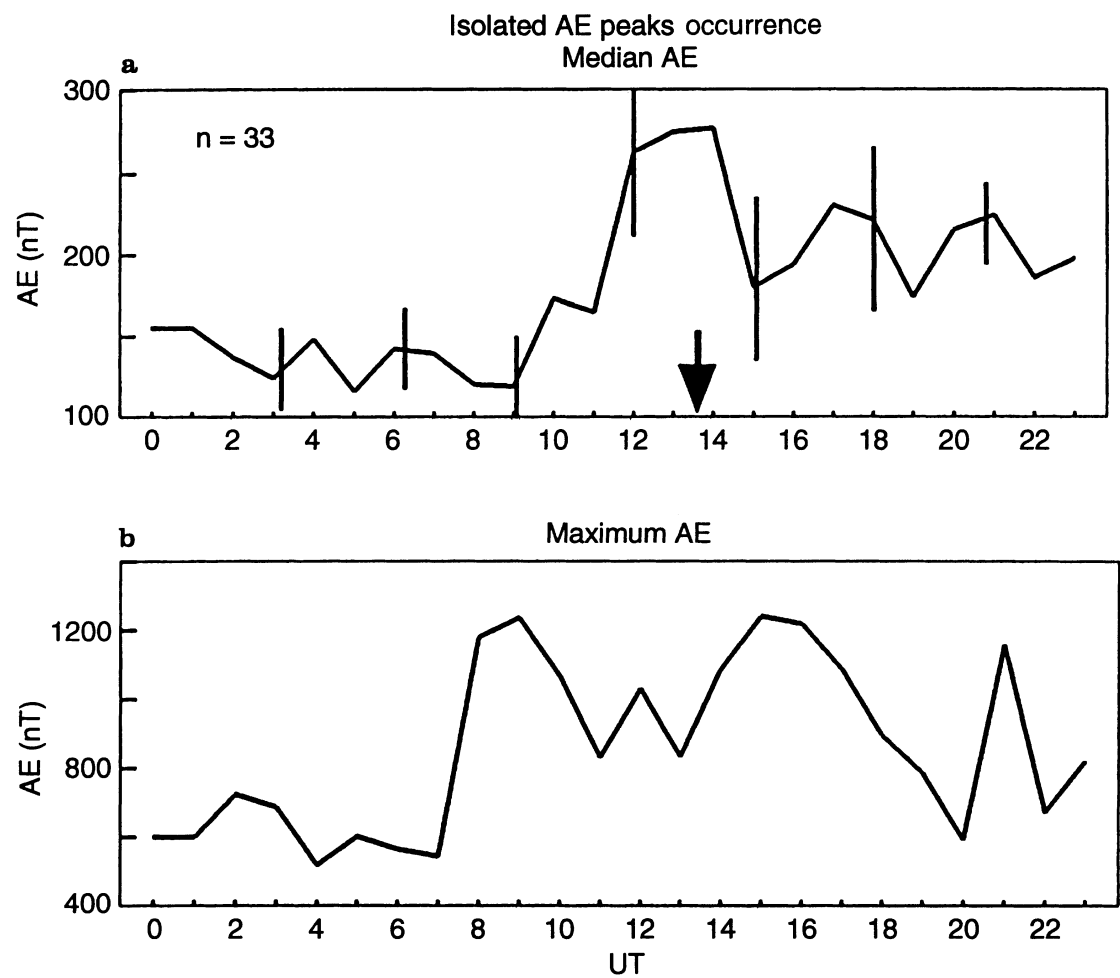

Fig. 2a,b. Statistical analysis of 33 isolated auroral substorm events. The error bars are indicated for the a median values. b All the days were scanned for maximum AE values

elsewhere a second phase of this study was to observe whether the same trend appears over a much larger data base. For comparison, a cycle starting in 1957 (i.e. at the time when the first AE-indices became available) to 1965 was considered (Fig. 3). In this study the analysis was applied to the entire AE data and not only to isolated

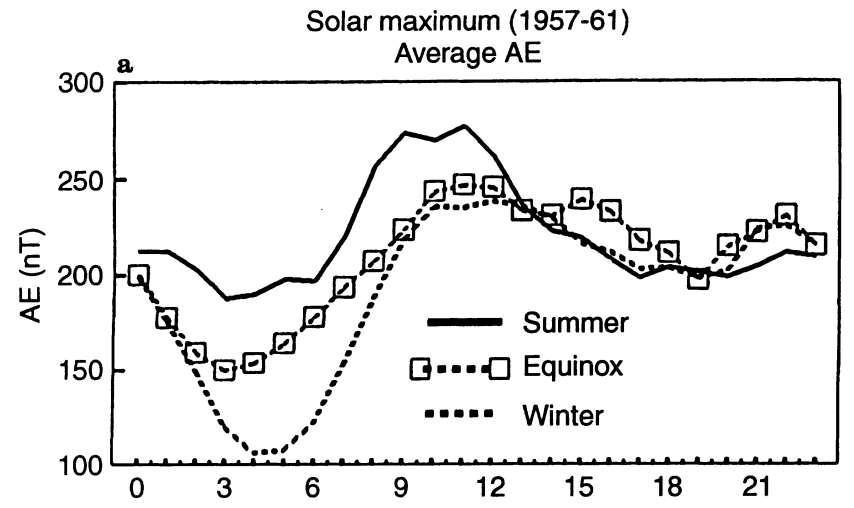

Solar minimum (1962-65)
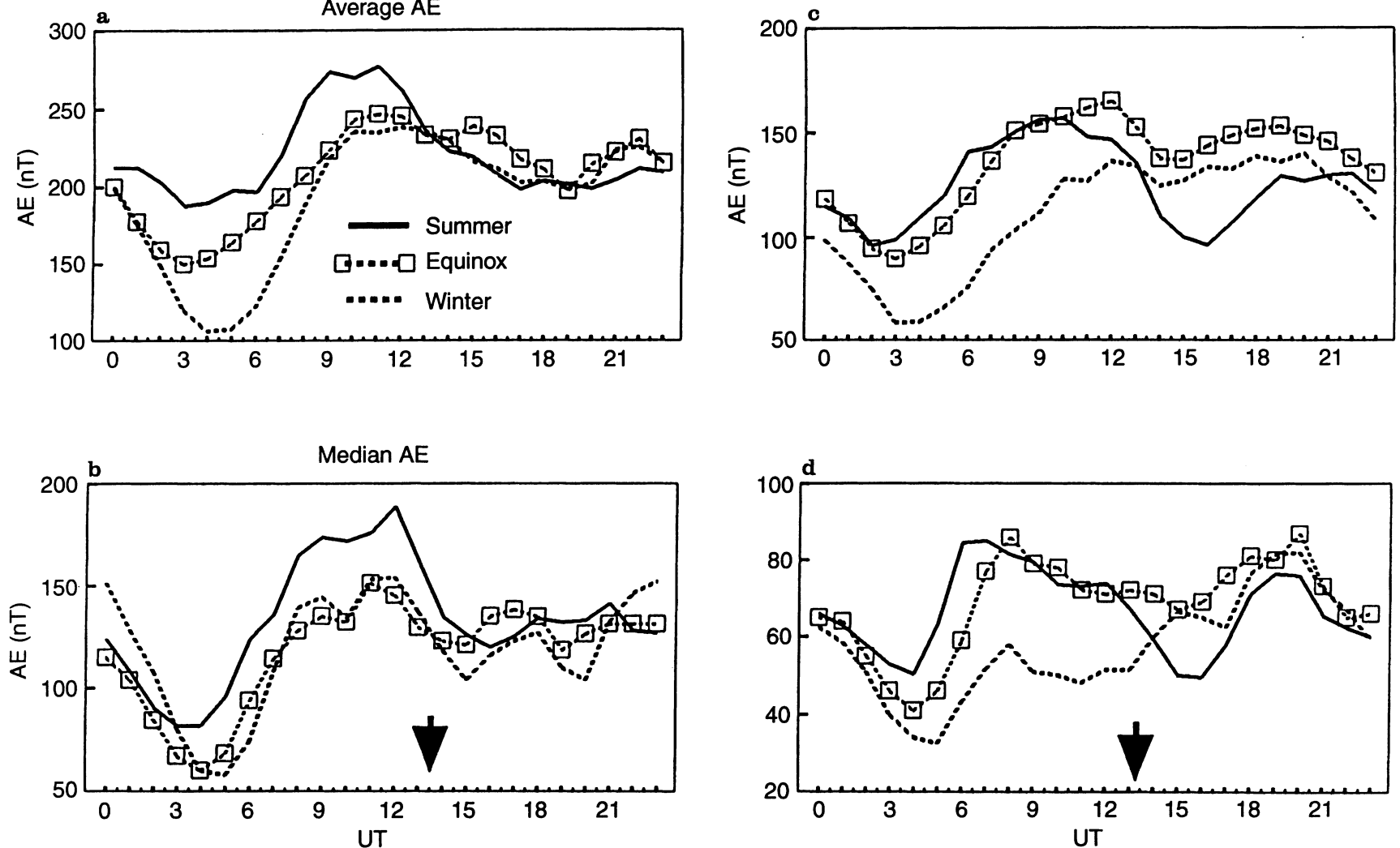

Fig. 3a-d. Average and median trends in the hourly AE-index (complete data) at different seasons at sunspot maximum and minimum. The standard errors (not shown for clarity) did not exceed 10\% of the nominal AE values (the same applies to other diagrams) 
events as in Figs. 1 and 2. Both average and median variations in AE-indices are shown in the UT time frame on the seasonal basis (summer: May-July, winter: November-January, and equinox: February-April and August-October). The standard errors, which did not exceed $10 \%$ of the nominal values, are not indicated for clarity in these and in subsequent diagrams. It is clear that the bulk of auroral activity, both at solar maximum and minimum, shows a similar trend as depicted in Figs. 1 and 2. Thus, there is a relatively narrow maximum in AE at 10-12 UT, for solar maximum and a broad maximum (07-19 UT) for solar minimum. Although the region of a clear maximum is sometimes difficult to define (for sunspot minimum) there is a consistent narrow minimum in auroral activity at $03-04$ UT throughout this cycle.

For comparison, average diurnal AE-indices for two solar cycles (21 years) are given in Fig. 4. Figure 4a, b refers to the average values of the AE-index for each hour (0-23 UT) for all the days within a specific season group (for two solar cycles). It is evident that for the first cycle (1957-1968) a distinct UT pattern in the auroral disturbance is present: a minimum between 3-6 UT is followed by a broad maximum (9-18 UT), with a
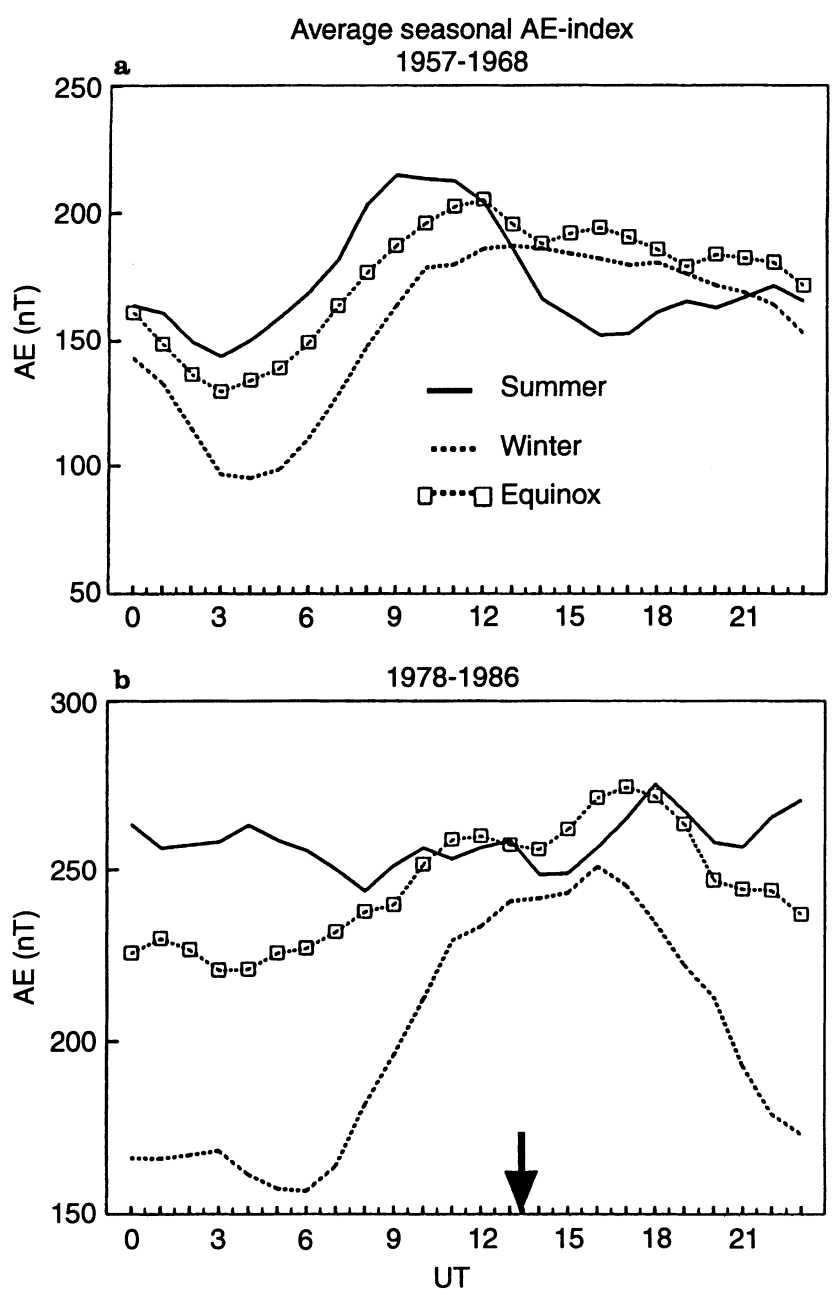

Fig. 4a, b. Average seasonal AE-indices found for two solar cycles and for each UT hour distinct peak westward of LM (Fig. 4a). The UT trend is not however preserved for all seasons during the second cycle (1978-1986) since there is no specific maximum and minimum in summer and there is a less clearly defined diurnal pattern for equinox (Fig. 4b). On the other hand the winter trend is maintained over the two solar cycles; i.e. a well-defined minimum at 3-6 UT is followed by an extended maximum. Note that the maximum for the winter $\mathrm{AE}$ for the second cycle is much better defined than for the first cycle, being well centred on LM (Fig. 4b).

As examples, the diurnal trends can be also seen in Fig. 5a, b in scatter diagram forms, for individual AEindex values for all the winters in 1978-1981 (solar maximum), and for all individuals AE-indices (for the two solar cycles) associated with large substorms (i.e. $\mathrm{AE}>1000 \mathrm{nT}$ ). The latter was found first by detecting absolute maxima for each hour (00-23 UT) and for each year. These individual maximum values were then plotted (in a scattered point form) for all 21 years; this gives a good representation of the maximum auroral electrojet activity over two solar cycles. It can be seen that out of six severe storms recorded within 21 y (AEindex $>2000 \mathrm{nT}$ ) five occurred between 8-15 UT. No large storms (AE-index $>1500 \mathrm{nT}$ ) occurred between 05-07 UT.

Figure 6 summarises the general trend in the median AE-index derived for the two cycles. Altogether 7510 days (and 180240 data points were used in this analysis; for the seasonal distribution of data see Fig. 7). It is quite evident that the diurnal UT effect is strongest in winter, intermediate in equinox and weak in summer.

The preferential occurrence of substorm onsets is of special interest in the space climatology. An attempt was made to define the probability of occurrences of the enhanced electrojet currents of different magnitudes (Fig. 7). The histograms show here the percentage occurrences (in 3-h intervals) of the AE indices in excess of $500 \mathrm{nT}$ (all more intense substorms, category 1), strong substorms $(\mathrm{AE}>1000 \mathrm{nT}$, category 2), very strong substorms (AE $>1500 \mathrm{nT}$, category 3), and severe substorms (AE > $2000 \mathrm{nT}$, category 4). All the data (for the two solar cycles and for each hour) were used in this analysis. It is evident that the UT effect for category 1 is strongest for winter showing the maximum between 12-18 UT, centred on LM (Fig. 7a). It is still present for equinox but it is absent for summer (Fig. 7c). The trend for more intense substorms only (category 2) indicates a diurnal maximum at 12-18 UT irrespective of the seasons. A limited number of strong and severe substorms indicate the same diurnal trend for equinox and summer, with a maximum for winter being somewhat earlier. Note that the time interval 03-06 UT can be regarded as the quietest period in the auroral ionosphere.

\section{Conclusions and discussion}

Relatively simple statistical analysis applied to $21 \mathrm{y}$ of hourly AE-indice data and spanning two solar cycle 

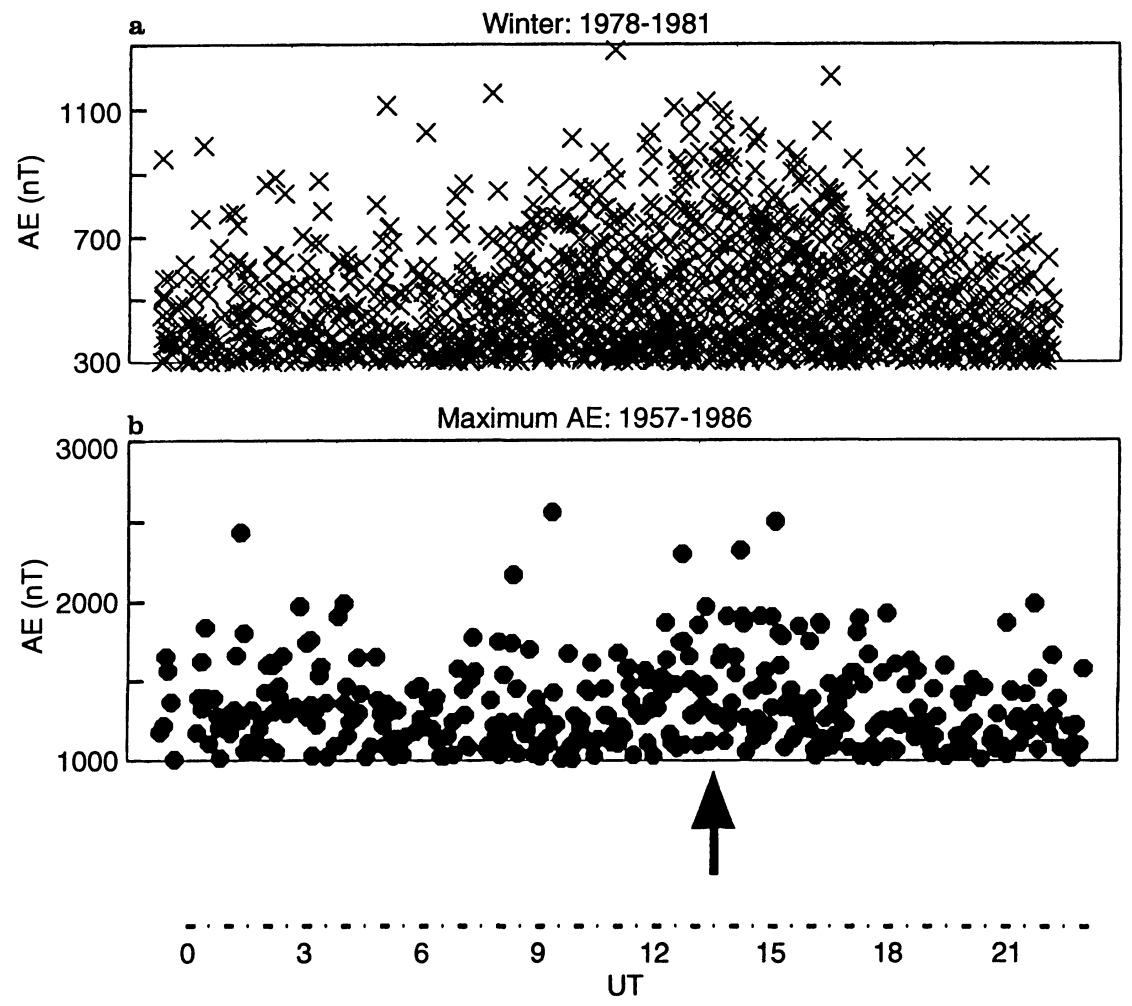

Fig. 5a, b. A scatter diagram of all the hourly AE-indices for winters 1978-1981 as well as a scatter diagram of all the hourly values of AE-index in a range of values: $1000-2500 \mathrm{nT}$, for two solar cycles revealed the following morphological features in the universal occurrence time of auroral substorms:

a. There is a distinct universal time effect in the occurrence of auroral disturbances which tend to peak between about 09-18 UT, reaching minimum between 03-06 UT. The diurnal minimum has been consistently observed for all northern winters for two cycles: 19571968 and 1978-1986, and for all the seasons during the first solar cycle. The diurnal distribution of AE-index was uniform for summer and showed only a weak diurnal trend for equinox during the second cycle.

b. The diurnal UT effect on the whole is strong in winter, intermediate in equinox and weak in summer.

c. The occurrence probability of strong magnetic disturbances $(\mathrm{AE}>1000 \mathrm{nT})$, irrespective of the sea-

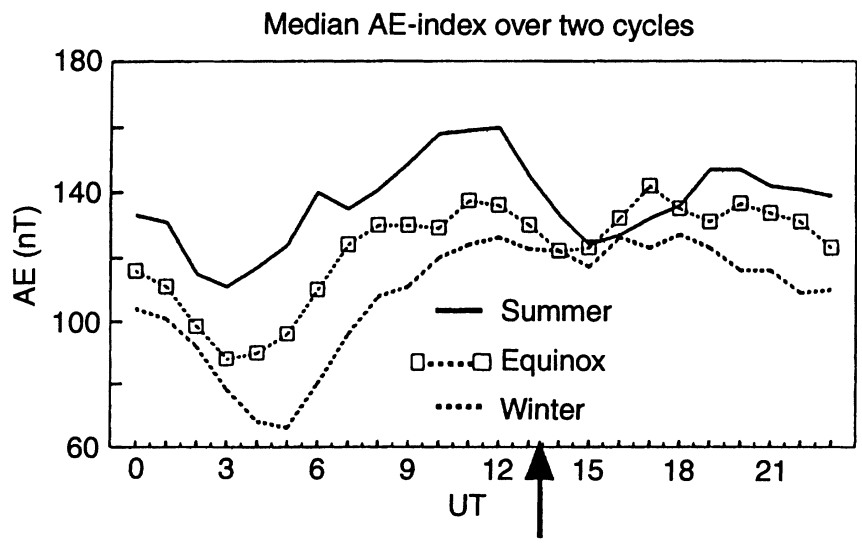

Fig. 6. Overall trends in the median values of AE-index for the two solar cycles and for different seasons son, is highest between 12-8 UT whereas the quietest period is between 03-06 UT.

d. Out of six severe auroral storms (AE-index $>2000$ nT) five occurred between 08-15 UT.

The first implication of the selective occurrence of auroral substorms is that the Eastern Siberia, Japan and Australia (sector 1) are at night time when the preferred onset of substorms takes place, particularly during northern winter. Europe (sector 2) and Eastern America (sector 3) are then mostly in the day time. The minimum period of auroral activity (3-6 UT) coincides with the near-midnight conditions in sector 3 , early morning in sector 2 and with the afternoon in sector 1 .

The particle precipitation and riometer auroral absorption measurements, as discussed in the Introduction, support the present findings; the auroral substorm intensity seems to be significantly larger over Alaska (and therefore close to the sector 1) than over Europe and Eastern America (sectors 2 and 3). The analysis of the AE-index by Allen and Kroehl (1975) indicates that the UT effect is also present on the yearly basis, using more frequent samples of the AE-index (see the Introduction). Finally, Hajkowicz (1984) presented a histogram of the onset magnetic disturbances using the local magnetic $\mathrm{K}$-indices for four auroral stations positioned polewards of sectors 1 and 2. The magnetic disturbance onsets were twice as frequent and much narrower (at 09-12 UT) for sector 1 than the onsets for sector 2.

The UT effect has to be evaluated for the possibility of its being introduced by a bias such as the uneven longitudinal distribution of the auroral magnetic stations whose data is used to compute the AE-index. Allen and Kroehl (1975), after carefully analysing the latitu- 

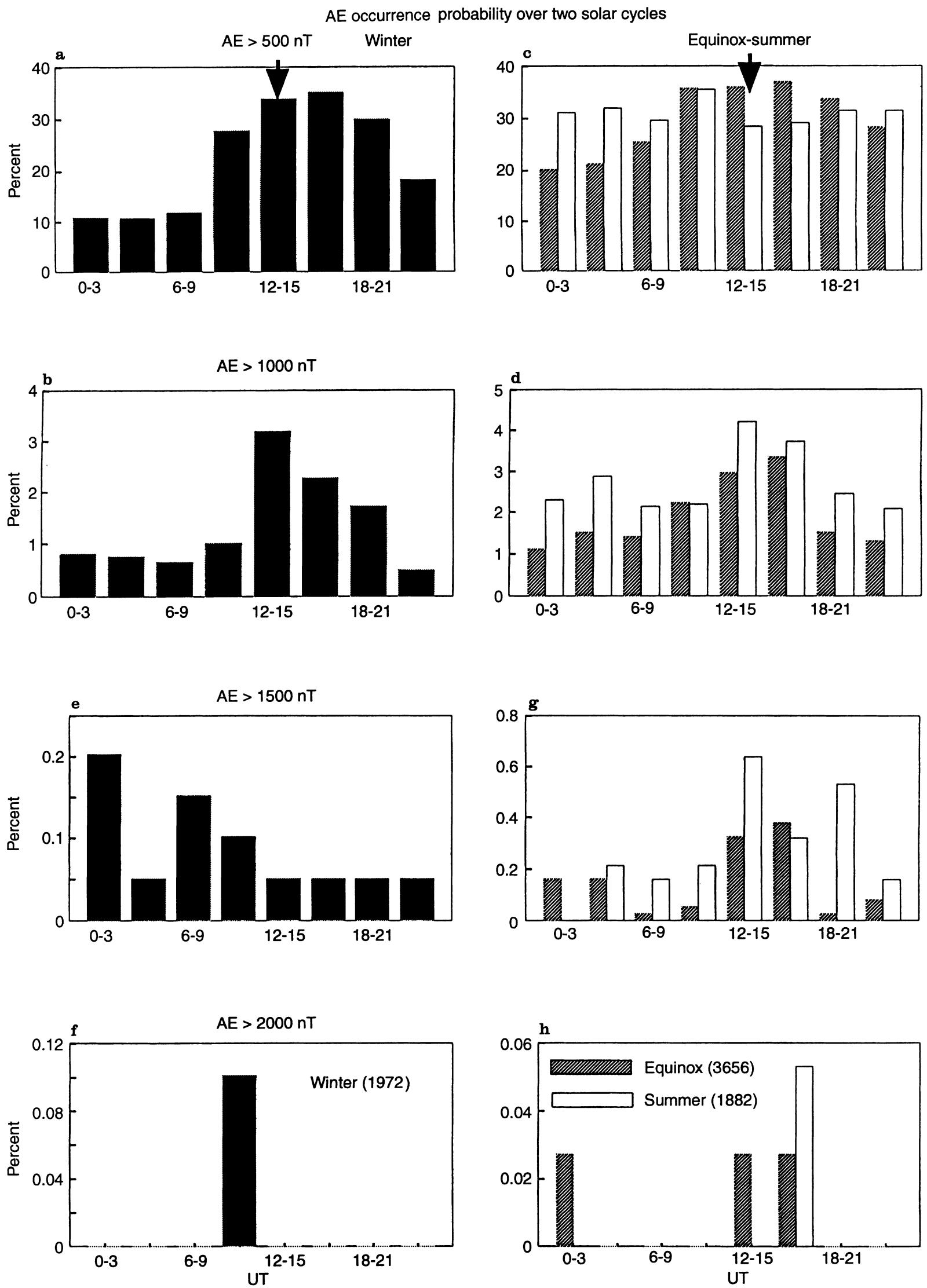

Fig. 7a-h. Probabilities of occurrences of the indicated AE-index values for the two solar cycles and for different seasons. The numbers of days used in the analysis for each season are indicated in the brackets 
dinal and longitudinal positions of these stations, concluded that it is unlikely that the stations' positions would introduce the observed universal time effect. They suggested that the UT effect is more fundamental and reflects an interaction between interplanetary magnetic field orientation and the Earth's magnetic dipole inclination. A similar suggestion, regarding UT effects in auroral particle precipitation, was given by Maehlum (1968) who pointed out there are large UT variations during the day in the angle between the Earth's magnetic axis and the Sun-Earth line. The change in the orientation of the Earth's field relative to the direction of the solar wind can cause 'wagging' in the Earth's magnetotail and thus affect the longitudinal distribution of the particle precipitation.

Another aspect evident from the present study is a seasonal variation in the UT effect; it is considerably more pronounced in winter than for equinox and summer. This difference became particularly obvious in the 1978-1986 solar cycle. During this solar cycle the AE-index showed no UT effect for summer and a weak UT effect for equinox. On the other hand in winter the UT effect was pronounced. The summer variation in the AE index might be affected by a large increase in the conductivity in the auroral region when most of the auroral zone is in the day time sector as pointed out by Berthelier (1976) and Weimer et al. (1990). This would obscure the UT variations due to a change in the SunEarth magnetic configuration. However, the UT effect should be present (if AE-index was available) in the southern auroral zone which is then in winter. Since auroral disturbances occur simultaneously in the conjugate regions (see Hajkowicz, 1990 for the conjugate auroral riometer study) in the southern and northern auroral zones it follows that the universal time effect may extend also to summer but it obscured by the higher ionospheric conductivity in the summer hemisphere. It appears that during at least some solar cycles the UT effect can be still well defined even in the summer hemisphere (as it was in 1957-1968). In addition the UT effect becomes quite distinct even in summer for strong magnetic disturbances (AE $>1000 \mathrm{nT}$ ) which may override the masking effect of the increased conductivity.

It is of considerable interest that almost identical results as presented here were obtained by Basu (1975) (see Introduction). She used a similar analysis for a much shorter period and found distinct auroral disturbance minimum at $04 \mathrm{UT}$ and maximum at $16 \mathrm{UT}$ for winter only; the trend was largely absent in summer. She pointed out that this trend is consistent with the prediction of the UT winter variation of the KelvinHelmholtz instability at the flanks of the magnetosphere (as derived by Boller and Stolov, 1970). However the theoretical model of the instability predicts an opposite effect in summer which is not observed in the present analysis for intense magnetic activity and for the first solar cycle. The Kelvin-Helmholtz instability shows little diurnal variation in equinox which again disagrees with the UT effect present in this period.

Acknowledgements. This project was supported by Telstra (Australia) grant 427-424-013-101. The AE data were obtained from the Internet site of the National Geophysical Data Center, Boulder, Colorado. I am grateful to Drs G. G. Bowman and H. Luhr for their helpful discussion on this subject.

Topical Editor D. Alcaydé thanks C. P. Price for his help in evaluating this paper.

\section{References}

Allen, J. H., and H. W. Kroehl, Spatial and temporal distributions of magnetic effects of auroral electrojets as derived from AE indices, J. Geophys. Res., 80, 3667-3677, 1975.

Basler, R. P., Radio wave absorption in the auroral ionosphere, J. Geophys. Res., 68, 466-4681, 1963.

Basu, S., Universal time seasonal variations of auroral zone magnetic activity and VHF scintillations, J. Geophys. Res., 80, 4725-4728, 1975.

Berkey, F. T., A comparison of the latitudinal variation of auroral absorption at different longitudes, J. Atmos. Terr. Phys., 35, 1881-1887, 1973.

Berthelier, A., Influence of polarity of the interplanetary magnetic field on the annual and the diurnal variations of magnetic activity, J. Geophys. Res., 81, 4546-4552, 1976.

Boller, B. R., and H. L. Stolov, Kelvin-Helmholtz instability and the semiannual variation of geomagnetic activity, J. Geophys. Res., 75, 6073-6084, 1970.

Davis, T. N., and M. Sugiura, Auroral electrojet activity index AE and its universal time variations, J. Geophys. Res., 71, 785-801, 1966.

Driatskiy, V. M., A study of the space and time distribution of auroral absorption according to observations of riometer network in the Arctic, Geomagn. Aeron., 6, 828, 1966.

Hajkowicz, L. A., The onset time interval of geomagnetic disturbances in the conjugate areas, Planet. Space Sci., 32, 819-823, 1984.

Hajkowicz, L. A., The dynamics of a steep onset in the conjugate riometer absorption, Planet. Space Sci., 38, 127-134, 1990.

Hajkowicz, L. A., Universal time effect in the occurrence of largescale ionospheric disturbances, Planet. Space Sci., 40, 1093-1099, 1992.

Hajkowicz, L. A., Ionospheric response to auroral substorms during sunspot maximum (1980-82), Ann. Geophysicae, 13, 95-104, 1995.

Hajkowicz, L. A., Equatorial ionospheric response to isolated auroral substorms over a solar cycle (1980-85): evidence of longitudinal anomaly, Ann. Geophysicae, 14, 906-916, 1996.

Loughnan, C. J., Longitudinal dependence of radiation-belt scattering, and primary auroral particles, Planet. Space Sci., 8, 13-22, 1961.

Maehlum, B. N., Universal-time control of the low energy electron fluxes in the polar regions, J. Geophys. Res., 73, 3459-3468, 1968.

Mayaud, P. N., Derivation, meaning and use of geomagnetic indices, Geophysical Monograph 22, American Geophysical Union, Washington, D.C., 1980.

Stenbaek-Nielsen, H. C., Indications of a longitudinal component in auroral phenomena, J. Geophys. Res., 79, 2521-2523, 1974.

Weimer, D. R., Maynard, N. C., Burke, W. J., and C. Liebrecht, Polar cap potentials and the auroral electrojet indices, Planet. Space Sci., 38, 1207-1222, 1990. 